\title{
Duodenal Carcinoma
}

National Cancer Institute

\section{Source}

National Cancer Institute. Duodenal Carcinoma. NCI Thesaurus. Code C4803.

A carcinoma that arises from the duodenum. The vast majority of cases are adenocarcinomas. 